\title{
WHY WE SHOULD CONSIDER SEX (AND STUDY SEX DIFFERENCES) IN ADDICTION RESEARCH
}

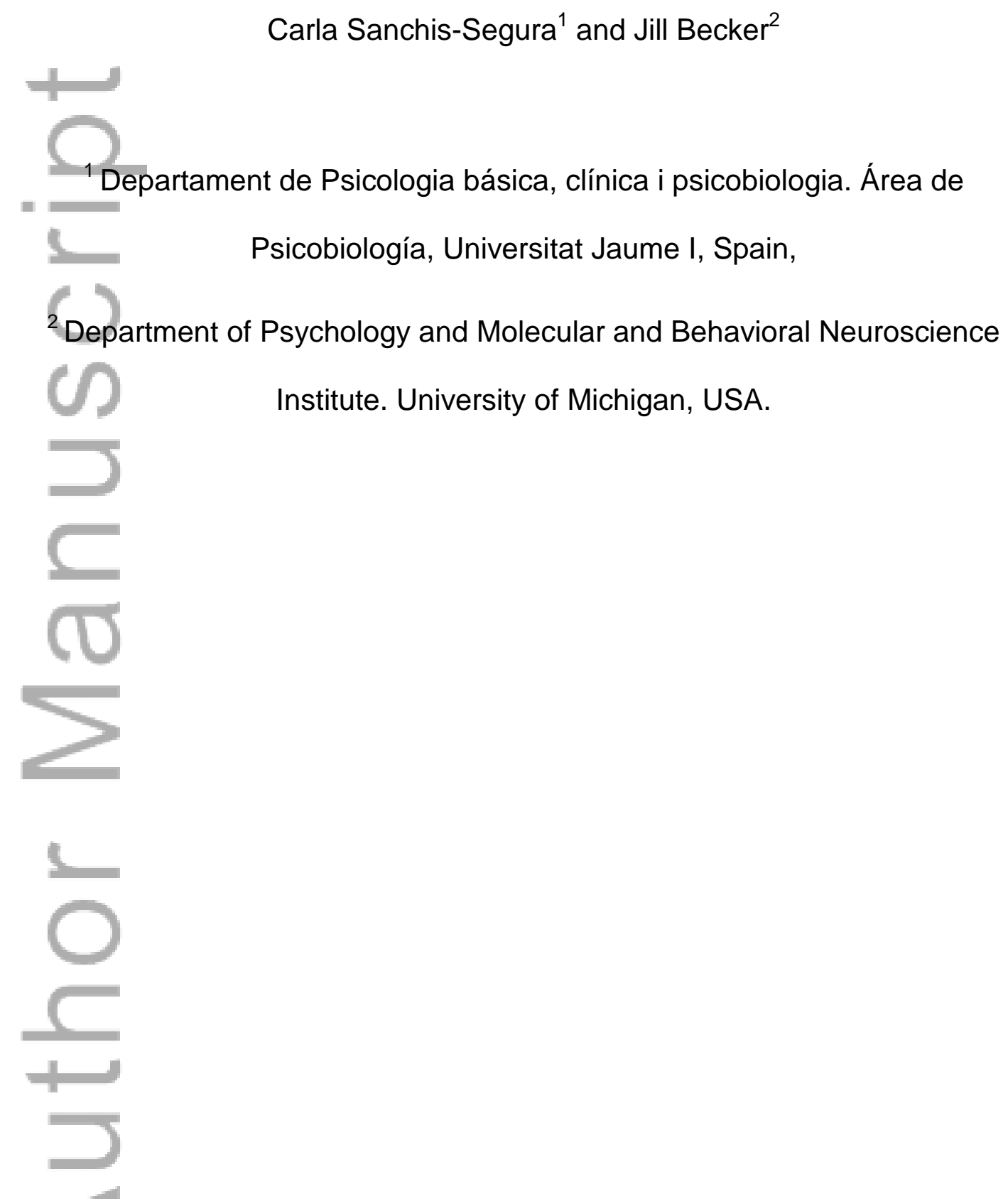

\section{Correspondence to:}

This is the author manuscript accepted for publication and has undergone full peer review but has not been through the copyediting, typesetting, pagination and proofreading process, which may lead to differences between this version and the Version of Record. Please cite this article as doi: 10.1111/adb.12382

This article is protected by copyright. All rights reserved. 
Jill B. Becker. University of Michigan. 205 Zina Pitcher Place. Ann Arbor, MI 48109. jbbecker@umich.edu

\section{ABSTRACT}

Among mammals, every cell has a biological sex, and the sex of an individual pervades its body and brain. In this review we describe the processes through which mammals become phenotypically male or female by organizational and activational influences of genes and hormones throughout development. We emphasized that the molecular and cellular changes triggered by sex chromosomes and steroid hormones may generate sex differences in overt physiological functions and behavior, but they may alternatively promote endpoint convergences between males and females. Clinical and preclinical evidence suggest that sex and gender differences modulate drug consumption as well as of the transition towards drug-promoted pathological states such as dependence and addiction. Additionally, sex differences in drug pharmacokinetics and pharmacodynamics will also influence dependence and addiction as well as side effects of drugs. These effects will further interact with socially gendered factors to result in sex differences in the access to, engagement in, and efficacy of any therapeutic attempt. Finally, we maintain that "sex-sameness" is as important as "sex differences" when building a complete understanding of biology for both males and females and provide a framework with which to classify and guide investigation into the mechanisms 
mediating sex differences and sex-sameness.

Key Words: sexual differentiation, sex differences, sex sameness

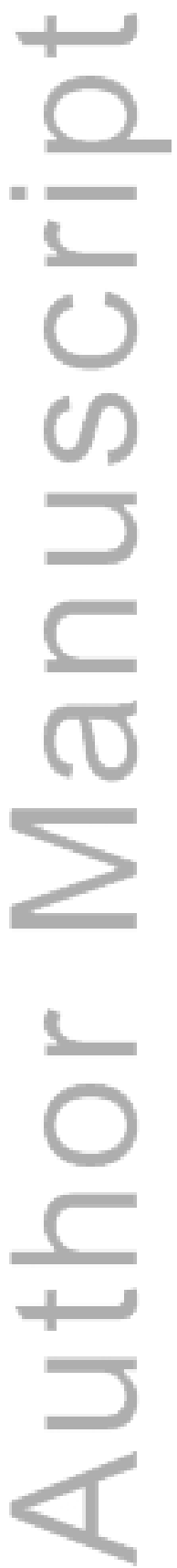

This article is protected by copyright. All rights reserved. 


\section{Abbreviations list}

Sry: Sex-determination chromosome Y; also known as TDF (testis-determining factor).

LncRNA: Long non-coding RNA

miRNA: MicroRNA.

FoxL2: Forkhead box L2 (also known as BPES/ BPES1)

CYP2C11: Cytochrome P450, subfamily 2, polipeptide 11. Male specific steroids 5- $\alpha$-reductase isozyme.

CYP2C12: Cytochrome P450, subfamily 2, polipeptide 12. Female specific sulfate $15 \beta$ hydroxylase isozyme

CPP: Conditioned place preference

THC: Tetrahydrocannabinol

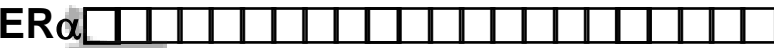

Oprm1: Mu opioid receptor gene.

GR/GR: Glucocorticoid receptor gene/ protein

CRH: Corticontropin releasing hormone.

This article is protected by copyright. All rights reserved. 


\section{1.- What is sex and what is gender?}

Any organism's activity is the result of a multilayered network of systems composed of cells. Inside each cell the elementary nodes of this network (genes and gene products) maintain a continuous dialog that sustains, updates or redefines cellular phenotypic characteristics. The cellular phenotype dictates the ongoing activity of a cell within its corresponding organ and system, thus finally limiting the range of potential responses and interactions of an individual with its surrounding macro-environmental factors. However, because most of the cellular elements involved in this interactive process are subjected to direct or indirect extracellular regulation, this cellular dialog is itself part of those produced at higher order biological modules (organs and systems) and of that established between the individual with its external (physical and social) environment.

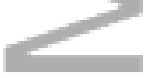

Every cell has a biological sex, and so the sex of an individual pervades this complex network in its entirety. In mammals and other (but not all) vertebrates, sex of the gonad is imposed by specific genes, and the expression of these genes "may interact with genotype in a manner similar to other environmental factors" (Ober et al., 2008). Some sex-specific elementary nodes (genes and gene products) are present and bias the activity and organization of the organism's network from its initial constitution. As a result, a larger number of nodes and their reciprocal interactions become sex-biased. This, in turn, results 
in sex differences on the organization and activity of higher order biological modules (cells, organs and systems). In this way, sex becomes an unavoidable multilayered biological context biasing the determination of the individuals' traits and their responses to environmental challenges and insults. Accordingly, we define sex as a dynamic but stable biological trait of organisms that encompasses genetic, epigenetic, cellular (for our purpose, mostly but not exclusively neural), neurochemical (hormonal and non-hormonal) and morphological variability (figure 1).

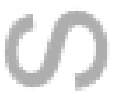

Gender is concerned with the inter-individual projection and embodiment of sex, arising from and manifesting from a differential interaction of sexed humans ${ }^{1}$ and their physical, social and cultural environments. These environments are themselves different for (or have different probability of being encountered by) individuals, depending on their perceived sex (whether someone thinks they are a male or a female), thereby reinforcing or opposing the already sex-biased individuals' behavior (figure1).

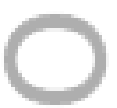

In this text, we will be using the term "sex" as including all of its dimensions (that is, gender, too) but when using "gender" we will be singling out the sex-biased interactions of individuals within their culture and their external environment.

\footnotetext{
1 Other social animals display sex roles and sex-biased interactions with their environment that can be considered as "gendered behavior". However, these gender-related manifestations are mainly observed in the natural (social and physical) environments of these species, a condition rarely met in preclinical biological research. Therefore, in this text we will use gender in the context of human behavior.
}

This article is protected by copyright. All rights reserved. 


\section{2.- How does sex matter?}

In mammals, sex is initially a genotype that becomes a multilayered and highly plastic phenotype (see article by Becker et al in this volume). Traditionally, although still common, views of sexual differentiation often rely on a simplified version of the "organizational-activational hypothesis" proposed by Phoenix and colleagues (1959). Thus, sexual differentiation has been often pictured as a "relay race" with chromosomal sex playing an initial role in gonadal differentiation and gonadal steroid hormones accounting for binary sex-related differences thereafter (figure 2A). The traditional "gonad-centric" view of sexual differentiation has been shown to be an over-simplification (Arnold, 2009; 2012), however, and is being replaced by the notion that both, steroid hormones and sex chromosomes are proximate agents on the multifactorial causation of sex differences and convergences (see figure 2B), many of which are expressed as a continuum.

According to this new scheme, the primary (already present at the zygotic stage) agents of sexual differentiation reside on the sex chromosome complement, with males having one $\mathrm{Y}$ and one $\mathrm{X}$ chromosome and females carrying two $X$ chromosomes. As shown in figure 3 , this results in, at least, 5 genomic sources of sexual bias: 1) There are genes (e.g., Sry) solely contained in the $\mathrm{Y}$ chromosome that will only be expressed in the cells of some tissues and organs of males; 2) Early in development one $X$ chromosome of $X X$ individuals is epigenetically silenced (Plath et al., 2002). Nevertheless, around 
$25 \%$ of X protein-codifying genes (Carrell and Willard, 2005), and an unknown number of LncRNA- (Reinius et al., 2010) and miRNA-genes (Morgan and Bale 2012), escape this inactivation process and are expressed at higher levels in XX cells (for a review see Berlecht et al., 2011); 3) The large heterocromatin bulk provided by an X-inactivated chromosome may act as "a sink" sequestering epigenetic factors required for silencing at autosomic loci, then leading to the enhanced expression of their genes in XX cells (Wijchers and Festenstein 2011); 4) Some of the genes contained in both the $X$ and the $Y$ chromosome (and therefore considered "homologous") actually produce different protein isoforms (Bellot et al., 2014); and 5) XX cells are subjected to parental and maternal imprint on their $X$ chromosomes, whereas $X Y$ cells are only affected by maternal imprinting (for a review on this and other aspects of sex differences and imprinting, see Bourc'his and Proudhon, 2008; for examples of its relevance on brain development see Gregg et al., 2010a,b).

As a consequence of these constitutive genomic biases, the activity of $X X$ and $X Y$ cells is intrinsically different, even when they are isolated in culture (Arnold and Burgoyne, 2004). Similarly, $X X$ and $X Y$ embryos show ample gene expression differences before gonadal differentiation occurs (Kobayashi et al., 2006). Therefore, the $X X-X Y$ inequality provides a set of inherent genetic and epigenetic sex-differences that produce an early sex-biased departure point for the individuals' development (but that can also be activated and translated into 
cell activity changes to produce or reduce other sex differences throughout an organism's life-span; Davies and Wilkinson, 2006; Arnold 2009; 2012).

The next crucial step in sexual development is gonadal differentiation, in which the $Y$-linked Sry gene is considered to be a crucial player (Brenan and Capel, 2004). Sry causes testes development that leads to testosterone and $\mathrm{MIH}$ release in $X Y$ developing individuals that act to masculinize internal and external genitalia. In XX embryos, the lack of Sry and the sustained expression of some "anti-testes genes" (i.e., FoxL2; Georges et al., 2013) are responsible of an also active process of gonadal differentiation towards ovaries that result in a differently timed secretion of estrogens and progestins. Thus, gonadal hormones provide a divergent internal milieu that is translated during development into permanent organizing effects on many of an organisms' tissues and organs, including the brain.

These so-called 'organizational effects' are the consequences of the actions of steroid hormones on several organs and tissues during a sensitive period, which result in persistent anatomical and functional differences (or convergences) between males and females. In the brain and other non-genital organs this organizational sensitive period is not restricted to prenatal development, but extends (although showing a substrate time-declining sensitivity) till the end of adolescence (Schultz et al., 2009; Juraska et al., 2013). On the other hand, the activational effects are seen mostly post-puberty 
and are reversible (in hours to weeks). The distinction between organizational and activational effects is mainly a conceptual one, which probably better illustrates a different state of the cellular substrate than a different mode of action of steroid hormones (Arnold, 2009). In fact, sensitive periods derive from cell plasticity and are better described as a property of some cellular ensembles (i.e., neural circuits; Knudsen, 2004), which in the case of the organizational/ activational dichotomy is (as a minimum) coincidental with a widespread reconfiguration of the neurons' methylome (Lister et al., 2013).

\section{$\infty$}

The molecular mechanisms underlying organizational/ activational effects of gonadal secretions involve fast pharmacological actions at externalized receptors (Srivastava et al., 2011) as well as more delayed actions derived involving gene expression changes after hormone binding on nuclear receptors (McCarthy, 2010) and pre- and post-transcriptional processing of miRNAs (Morgan and Bale 2012). A full description of these molecular mechanisms is beyond the scope of this article. Rather, here we would like to highlight that steroid hormones modify the cell number, structure and activity of different tissues and organs, resulting in direct and indirect consequences.

Direct consequences of organizational effects include the differential shaping of genital organs, the development of sexual secondary characteristics and the incorporation of sex-related differences in the structural organization of other organs, such as the brain. Brain organizational effects involve the promotion of 
neurons survival, synaptogenesis and other microanatomical changes that are maintained through epigenetic mechanisms (McCarthy, 2010; Lenz et al., 2012). On the other hand, the organisms' differential developmental processes also introduce a series of important, albeit indirect, consequences for the interactions of sexed individuals with their environment (see next section).

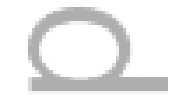

Therefore, there are two main proximal sources of sexual differentiation, namely sex chromosomes- and steroid hormones-effects. These two factors should not be regarded as mutually exclusive or temporally consecutive. Rather, they are concurrent and interacting (synergistic or antagonistic) sex-biasing influences on the organism's genomic activity. The quantification of how many genes displaying sex-biased expression in adult individuals is cumbersome as it significantly varies among tissues and organs (and probably within smaller anatomical units). Nevertheless, some studies are starting to provide initial numbers. Yang et al. (2006) reported that $50-70 \%$ of genes display sex-biased expression in mouse tissues, although this proportion is noticeably lower for the brain (13.6\%) than for other organs (i.e., liver, 72\%). These results might be interpreted to mean that the brain is less sexually biased than other organs (i.e., liver). However, it is also possible that sex differences in gene expression within some brain specific nuclei are diluted or masked by those occurring at other nuclei, leading to a bewildering description of these differences when whole brain is studied. On the other hand, at least for the liver, sex-biased expression of most (but not all) genes seems to be largely dependent on steroid- and non- 
steroid (i.e., GH) hormone effects during adulthood (Van Nas et al., 2009). Whether or not this also the case for sex-biased gene expression on the brain remains unknown and is likely to vary by brain region.

The size of these sex differences in gene expression also differs depending on the gene, the tissue and the organism studied. Probably the most extreme case of sex-biased gene expression described is the 500-fold difference for the transcripts of the CYP2C11 and CYP2C12 in the liver of male and female rodents, respectively (Waxman and O'Connor, 2006). However, either in the liver (86.6\%) or in the brain (99.2\%) most genes show a sex difference smaller than 1.2 fold (Yang et al., 2006). Rather than prioritizing the few genes that exhibit big sex differences and dismissing the rest, these two sets of sex-biased genes should be separately considered. Thus, the few genes showing big sex differences in expression are likely central nodes of sex-specific physiological networks (i.e., CYP2C11 and CYP2C12 encode for hydrolases involved in sexspecific pathways of steroid metabolism). Contrastingly, slightly sex-biased expressed genes (specially when present in a large number) are likely to bend the activity of networks operating in both, females and males (Yang et al., 2006).

Finally, it should be emphasized that the molecular and cellular changes triggered by sex chromosomes and steroid hormones may generate sex differences in overt physiological functions and behavior but, as hinted through 
all this section, they may alternatively promote end-point convergences between males and females (De Vries, 2004; Arnold, 2014). In other words, some sex differences are thought to be present in order to compensate for other sex differences that exist in the organism at the same or at other biological levels. Thus, for example, X-inactivation in the female (partially) compensates for the different number of $X$ chromosomes that males and females have. Similarly, estradiol seems to reduce (not produce) sex differences in the microanatomy of hippocampal neurons (McCarthy and Konkle, 2005), while testosterone seems to counteract the intrinsic higher vulnerability of $X Y$ cells towards some forms of neurodegeneration (Du et al., 2014). By the same token, sex differences at different tissues, organs and systems provide agonistic or antagonistic contributions to a phenotype of interest. Of special relevance in the context of this review is the fact that the adrenal glands, the placental tissue and the brain produce steroids. Therefore, blood levels of estradiol and progesterone do not necessarily reflect their concentrations in specific brain regions (Caruso et al., 2013) and brain regional differences in the contents of these hormones persist even when the gonads or the adrenal glands are removed (Konkle and McCarthy, 2011). This out-of-thegonads production of steroids has not yet been properly accounted by current models of sexual development, but together with of other forms of compensation, clearly indicate that sex-biasing effects ultimately need to be analyzed as a set of interactions at the organism level. 


\section{3.- How might sex and gender matter for drug abuse and addiction?}

Clinical and preclinical evidence suggest that sex and gender might be relevant modulators of drug consumption as well as of the transition towards drugpromoted pathological states such as dependence and addiction. Thus, as summarized in figure 4, gendered individuals differ in their probability of encountering drugs in the environment but also in the way their sexed bodies absorb, distribute and metabolize these substances. The different amounts and/or metabolites of bioavailable drugs will then interact with sexually differentiated brain systems. These sex differences in drug pharmacokinetics and pharmacodynamics will result in a plethora of wanted and unwanted effects that will affect the individuals' probability of seeking and taking drugs on future occasions as well as their probability of developing drug-related clinical conditions (such as dependence and addiction). These effects will further interact with socially gendered factors to result in sex differences in the access to, engagement in, and efficacy of any therapeutic attempt.

Preclinical studies have established that female rodents tend to display enhanced response to and motivation for most drugs of abuse, compared with male rats. These differences are largely dependent on the circulating levels of steroid hormones (for recent reviews, see Becker and Hu, 2008; Carroll and Anker, 2011), but there are also organizational effects of prenatal and pubertal

This article is protected by copyright. All rights reserved. 
hormones during development (Perry et al., 2013a). Thus, as supported by experiments involving adult gonadectomy/ exogenous hormone administration and estrous cycle phase correlations, estradiol enhances (and, in many cases, progesterone decreases) the pharmacological response to acute and repeated psychostimulants administration (i.e., behavioral sensitization), their reinforcing capabilities (i.e., CPP) as well as the motivation to self-administer them (Quinones-Jenab and Jenab 2012). Less information is available for nonpsychostimulant drugs, but studies involving opioids, alcohol and nicotine seem to follow a similar trend (Carroll and Anker, 2011; Becker et al.,2012).

It has been reasonably assumed that these behavioral sex-differences largely depend on the modulatory effects of gonadal hormones in several brain neurotransmission systems (for a review, see Becker et al., 2012). However, the same studies have also provided convincing evidence showing that these activational hormone effects are produced upon an already sex-biased system. This conclusion is sustained by three main clusters of data indicating that: 1) Females' enhanced motivation for drug-taking and enhanced psychopharmacological response to psychostimulants is attenuated by, but persists after, ovariectomy; 2) Exogenous estradiol administration enhances these effects in ovariecteromized and intact females but it does not have the same facilitating effects in males, regardless of their gonadal status; and 3) Testosterone administration and castration have a smaller impact, if any, in most of these behavioral differences 
Traditionally the behavioral sex differences that could not be accounted for by adult circulating hormone levels (e.g., "activational" effects) have been considered dependent on their "organizational" effects on the brain during an early sensitive period. However, this conclusion needs to be reframed within current views of sexual differentiation. As described in the previous section, it should be noted that: 1) Sexual differentiation is not restricted to the brain; 2) Sexual differentiation does not only occur during prenatal development; 3) Both sexual chromosomes and steroid hormones concurrently (synergistically and/ or antagonistically) contribute to the sexual differentiation of non-gonadal tissues and Organs; and 4) Sexual differentiation promotes direct and indirect consequences and both of these contribute to the sex-biased behavior of organisms.

Thus, although the most obvious locus to place sex-biased mechanisms accounting for sex differences in drug related behaviors is the brain, the contributions of other sex-biased organs should not be ruled out without specific assessment. In fact sex-differences on the pharmacokinetics of several drugs of abuse have been reported. These pharmacokinetic differences probably arise from the prominent sex differences on gene expression observed in the liver (Yang et al., 2006). Other constitutive traits of males and females (i.e., body composition) might also affect the amount of bioavailable drug, especially when highly lipophilic drugs (i.e., THC) are considered. This caution should be 
similarly applied to drugs used as pharmacological tools in preclinical research or in the clinical management of addicted patients. On the other hand, sexdifferences in other organs and systems might result in a differential intensity of side effects of abused drugs in males and females, also biasing their future consumption (for a proper coverage of all these topics, see Franconi et al., in this volume).

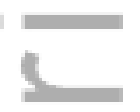

Focusing in the brain, anatomical and functional sex differences have been found in several neural circuits currently thought to play a major role in drug consumption and addictive behavior. These include neural circuits involved on motivation/ reinforcement, stress-reactivity and top-down inhibitory self-control, (for recent reviews, see Becker et al., 2012; Bisagno and Cadet, 2014; Becker and Noori in this volume). Circulating steroid levels modulate most of the differences observed within these circuits (Becker et al., 2012), hence mirroring what occurs for sex differences in other brain circuits not directly involved in reproduction (McCarthy and Konkle, 2005). Although direct evidence for hormone-mediated organizational effects on these circuits during prenatal development is virtually non-existent, the long-lasting remodeling that they suffer during adolescence is clearly influenced by gonadal (Becker, 2009; McCormick et al., 2010; Paus et al., 2010) and, probably, non-gonadal (i.e. adrenal; Spear, 2000) steroids' levels. These changes occur at different paces, starting by an increase on the activity of the ascending mesolimbic-mesocortical dopaminergic motivational system that only years after will be counteracted by

This article is protected by copyright. All rights reserved. 
the maturation of the inhibitory top-down systems of the prefrontal cortex. The differential timing of these maturational changes renders the adolescents' brain in an unbalanced state, which results in increased risk-taking behavior (Steinberg, 2008) and a special sensitivity towards addiction (Chambers et al., 2003).

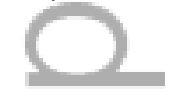

Appropriate genetic models to study sex-chromosomes effects have only recently become available (for a review on these models, see Cox et al., 2014). Therefore, evidence supporting the involvement of sex-chromosome effects on drug reinforcement/ addiction is still scarce and in, most cases, indirect. Thus, it has been suggested that sex chromosome complement might have a major role on the expression of GABA-, serotonin- and dopamine-related genes on the frontal cortex (Seney et al., 2013). Similarly, sex chromosome complement might also be involved in the observed sex differences in the motivation to consume saccharine (Seu et al., 2014) as well as in the habit formation for food (Quinn et al., 2007) and operant responding for alcohol (Barker et al., 2010). There data were obtained using the "four core genotypes" model, so they do not provide information on which specific $X-Y$ inequalities are at play. On the other hand, it is known that the Y-exclusive Sry gene (besides playing a key role gonadal differentiation) is expressed in the tyrosine hydroxylase-expressing neurons of the substantia nigra (Dewing et al., 2006) and VTA (Czech et al., 2012), where Sry transcripts regulate catecholamine synthesis and metabolism. Similarly, it has been reported that Sry polymorphisms affect brain ß-endorphin 
concentration (Botbol et al., 2011). However, the functional consequences of these Sry actions on the brain for drug abuse/ addiction remain to be explored. Therefore, further research on this topic, including clinical information on drug consumption/ addictive behavior of individuals with sexual aneuploidic conditions (i.e., Turner syndrome), is needed.

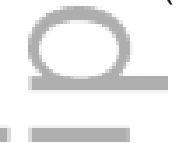

Finally, as mentioned in the previous section, sex-chromosome effects and steroid hormones alter the organisms' morphology and activity of other tissues and organs, leading to direct and indirect consequences. Among the later, it is obvious that from birth on and even more after puberty, individuals perceive themselves, and are also perceived by others, as sexed individuals. This results in a gender-biased experience and interaction with the environment, with males and females putatively having different opportunities, receiving different consequences for their acts and learning different coping strategies (see Becker, Glover Reed and McClellan in this volume).

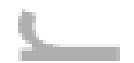

Drug abuse and related phenomena provide a clear illustration of the importance of differentially gendered environmental interactions and experiences. Thus, the observed higher likelihood (2-3 fold) of adult men to be diagnosed by a drug abuse/ dependence disorder seems to largely be a gender difference in opportunity (Van Etten et al., 2001). Indeed, traditionally women have had less opportunity to use marijuana, cocaine, hallucinogens and heroin (Van Etten et al., 1999). When the influence of drug availability is ruled out,

This article is protected by copyright. All rights reserved. 
women tend to increase their rate of drug consumption faster than men do (Brady and Randall, 1999; Lewis et al., 2014) and once they are addicted to a drug they can find more difficult to quit (Lynch et al, 2001). Preclinical studies also find a faster transition towards habit- and compulsive-like patterns of drug intake in females than in males demonstrating that biological differences may mediate these sex differences (for recent reviews, see Caroll and Anker, 2011; Quinones-Jenab and Jenab 2012; Fattore et al., 2014 and in this volume). On the other hand, women seek for help earlier (John, 1987; Hernández-Avila et al., 2004) and for different reasons (Weisner and Schmidt, 1992) than men do, showing also a differential adherence (Mertens and Weisner, 2004) and response (Fox et al., 2014) to therapeutic interventions.

Gendered experiences have long been considered within the realm of social sciences and not necessarily relevant (or at least not easily modeled) in biological research. This situation is changing with the fast growing increase of knowledge regarding epigenetic modifications of the genome, some of which are dependent upon sex-biased interactions with specific environmental factors. In rodents, for example, the sex of an individual is a major determinant of the quantity and quality of maternal care received (Moore and Morelli, 1979), which in turn results in a different epigenetic status of a large number of genes that might contribute to the establishment, maintenance or activation of sexual differences in the brain (i.e., ER $\alpha$; Edelmann and Auger, 2011) but that also may, directly or indirectly, affect some organisms' traits, diseases and 
behavioral dispositions. The reduced maternal licking of female pups might result in reduced methylation of the Oprm1 gene at the nucleus accumbens and at the caudate-putamen (Hao et al., 2011). Similarly, reduced maternal care decreases hippocampus $\mathrm{GR}$ and $\mathrm{CRH}$, while altering amygdala GABAA receptor subunit expression, then leading to an increased responsiveness of the stress axis (for a review, see Champagne and Curley, 2009). Although at present there is not evidence enough to link these gendered experiences with some of the observed sex-related differences in drug consumption/ addiction (i.e., higher impact of stress and negative emotional states on females drug relapse Becker et al., 2012; Bisagno and Cadet, 2014), they might serve as examples of how sex-biased environmental interactions alter the architecture and activity of the brain, hence promoting or reducing behavioral differences between males and females.

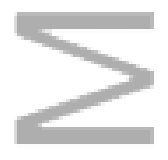

\section{4.- Sex differences and sex sameness: a framework for moving forward}

On the previous pages, we have consistently referred to sex differences. However, introducing sex as a relevant factor on biological research goes beyond collection of examples of isolated differences between females and males. The real challenge is to discern how and when the observed sex differences are established and what they mean for the biology and behavior of an individual. For these goals to be achieved a comprehensive "sex perspective" needs to be adopted. From the outset of this special issue we 
would like to highlight two basic ideas, which are neither new nor original but that are worth repeating: First, not all sex differences are alike. Second, sex "sameness" is as important as sex differences.

We agree with McCarthy et al., (2012) that there is a need to classify biobehavioral sex/ gender-related differences, and we think that this should be done according to three successive criteria as described in figure 5.

First, is the sex/ gender-related difference constitutive or contingent? Constitutive differences are those ordinarily found when comparing males and females, that occur under an ample variety of testing conditions and for which there is no identifiable trigger other than the biological sex of the subject. Contingent differences are those that only emerge under specific physiological states (i.e., injury, pregnancy, stress...) or in response to specific and identifiable stimuli or environmental situations (i.e., novelty).

Of note, standard testing conditions in preclinical studies have traditionally been set and optimized for male subjects. Testing females under these maleoptimized conditions might promote contingent sex differences. Further, the domain at which these differences appear might be misinterpreted. For example, Beiko et al. (2004) found that some of the sex differences observed in spatial navigation on the Morris' water maze task arise from a differential stress response of males and females to standard testing conditions rather than different learning/ memory capabilities or strategies.

This article is protected by copyright. All rights reserved. 
Second, once a constitutive or contingent sex difference has been identified, it needs to be classified according to the statistical characteristics of the difference. In this regard, three main levels can be distinguished:

-Dichotomous sex differences are those in which the variable of interest presents as a bivariate ("two-peaked") distribution with each sex displaying one of two alternative or competing phenotypic expressions (this can also include the presence or absence) of the trait in one sex. It is worth mentioning that based on current evidence, dimorphisms are expected to be largely restricted to reproduction in a broad sense (i.e., also including courtship patterns, etc.).

Average sex differences are those expressed in a continuum for which males and females differ in their mean averages, variance or both. These are expected to be the majority of the cases when studying neural and behavioral sex differences. To attain a more accurate interpretation of this kind of difference, reporting statistical significance ( $p$ values) is not enough and appropriate effect size measures need to be included. In this regard, there is a real need to include measures of effect sizes in any domain of biology (Nakagawa \& Cuthill, 2007), but in particular in biobehavioral studies with potential clinical or social consequences.

Effect sizes can be interpreted in terms of the percentiles or ranks at which two distributions overlap, in terms of the likelihood of identifying the source of a value, or with reference to known effects or outcomes (Coe, 2002).

This article is protected by copyright. All rights reserved. 
Therefore, effect size measures provide information on how big differences are (and not just on their reliability) in standardized units that can be compared across different studies and that ease their summarization though meta-analysis and similar approaches (another very important scientific tool that has only recently started to be incorporated in the drug addiction field; i.e., Noori, Helinksi and Spanagel, 2014).

-Number sex differences are those referring to a differential frequency or proportion of males and females exhibiting an otherwise identical feature (i.e., when a disease or phenotype is more prevalent in one sex). Number sex differences can superficially resemble average differences, however, number sex differences refers to differences on the absolute or relative frequency of individuals of each sex that display a trait whereas average sex differences refer to the distance between males and females' averages (i.e., means), the magnitude of dispersion estimators (i.e., range) or both on a continuously measured quantitative variable. Therefore, there is no possible overlap between number and average differences when a qualitative or multi-criteria outcome is considered. Conversely, when using a single quantitative criterion to define the outcome, the distinction between both depends on how it was measured and analyzed. Thus, for example, it has been reported that $50 \%$ of female rats choose cocaine over a highly palatable food pellet while only $15 \%$ of males make the same choice (Perry et al., 2013b). Expressed in this way,

This article is protected by copyright. All rights reserved. 
this a number difference affecting the frequency of a pre-defined outcome, but this difference might had been expressed as the groups' average preference for cocaine over food, as well.

Finally, the classification of sex differences should also consider their final significance at the functional level, then distinguishing between convergences and divergences. Divergences are those variations that make males and females distinguishable on one or more end-point features, whereas convergences are differences that compensate for other differences, making females and males more similar than they would be otherwise (see end of section 2). Examples of convergences are expected to grow as our knowledge of sex differences become more and more integrated, as it is clear that sexes need to remain compatible despite their different evolutionary pressures and ontogenetic point of departure (Ellengreen and Parsch, 2007). However, the existence of compensations might pose additional challenges for preclinical research. Thus, females and males often reach identical level of performance but they may do so using different behavioral strategies arising from different neural underpinnings. Therefore, measures more than just the quantification of performance can be needed to properly identify and describe behavioral sex differences.

The classification of sex-differences in this way is helpful for thinking about how to integrate the variable of biological sex into a coherent theoretical framework. It is important to also realize that males and females are both different and 
alike, and that both types of observations are scientifically relevant. As McCarthy and Konkle (2005, p.98) put it ten years ago "Understanding how the sexes are the same is just as important as how they differ, but the latter receives far less attention and little value as a genuine scientific finding". In fact, we even lack an agreed terminology to refer to the commonalities found between males and females. Thus, at the time of writing this piece the expression "sex sameness" retrieved 5 pubmed publications while "sex differences" retrieved 181223 reports (a number that will have increased by the time the reader set eyes on this article).

We maintain that "sex-sameness" is as important as "sex differences" when building a complete understanding of biology for both males and females. This also affects our social responsibilities as scientists. In this regard, reporting sex similarities is equally important as reporting sex differences. By not doing so, a distorted landscape of how sex affects brain function and behavior might be repeatedly portrayed, thereby fueling the misleading (sometimes, even mischievous) notion that males and females are more different than they really are. Indeed, the sole focus on sex-related differences has indirectly contributed to create a sketchy and distorted presentation of males and females as beings of "different planets" or with "two types of brains" that, echoing on old topics and prejudices, has gained fast and often uncritical social acceptance. Those scientifically sterile simplifications have also produced the equally simplistic prejudice that investigating sex differences is somehow inappropriate or

This article is protected by copyright. All rights reserved. 
inconvenient, something that (as we try to show here) could not be farer from the truth.

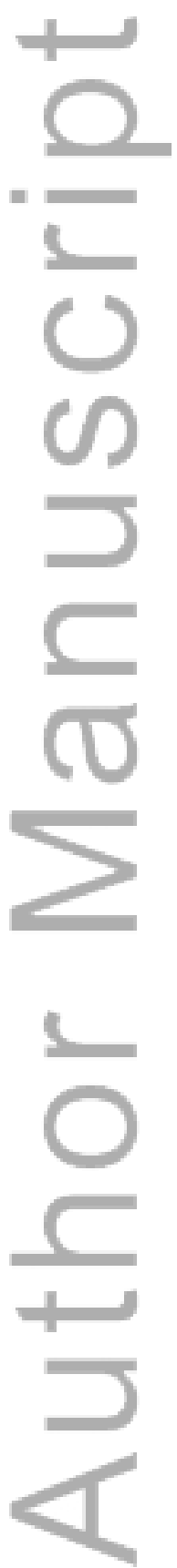

This article is protected by copyright. All rights reserved. 


\section{FIGURE LEGENDS}

Figure 1.- Defining sex and gender from a systems biology perspective.

Sex is a dynamic but stable biological trait of organisms that acts as a multilayered biological context biasing the determination of the individuals' characteristics and their responses to environmental demands. This context initially arises from a sex-specific genotype that together with other with other sex-differentiating agents (mainly steroid hormones) produces a sex-biased activity of the individuals' genotype. As a consequence, a sex biased phenotypic organization and function of higher order biological modules (cells, tissues, organs and systems) and a series of sex-biased behaviors are produced. In humans (and other social animals) sex includes a relational level (gender) based on the perceived sex that manifests on a differential interaction of sexed humans and their out-of-the-organism physical, social and cultural environments. These environments might themselves be different for (or have different probability of being encountered by) individuals differing on sex, then providing different opportunities and divergent consequences for sex-biased behaviors of gendered individuals.

\section{Figure 2.- Two models of sexual differentiation.}

According to traditional views of sexual differentiation (panel $A$ ) $X X$ and $X Y$ individuals would be basically indistinct till the gonadal expression of the $\mathrm{Y}$ linked Sry gene Sry expression would lead the development of previously undifferentiated gonads as testes or, in females, the lack of Sry would lead to ovary development of ovaries. In the first case, testes' secretions (mainly

This article is protected by copyright. All rights reserved. 
testosterone and Müller inhibiting hormone, $\mathrm{MIH}$ ) or their metabolites acting at a critical prenatal period would differentially organize in males several organs and tissues, such as the brain, then changing their "by default" organization (that observed in females); these structural sex-differences would remain largely silent till puberty, when a second (and more or less permanent) rise of gonadal steroid hormones would set them in motion, producing further sex-differences in physiology and behavior. On the other hand, if gonads develop as ovaries, no immediate secretions are produced and, in absence of "masculinizing" signaling, leading to the passive development of organs and tissues including the brain. Those feminine-differentiated tissues are activated by the raise of estradiol and progesterone from the ovaries.

In contrast, current views of sexual differentiation (panel B) pose unequal chromosome complement as primary sources of physiological disparity between males and females, some of which occur before gonadal differentiation. Sry is still considered a major agent of gonadal differentiation, but it is known that the expression (i.e. Sox9) and repression (i.e.FoxL2) of other genes is needed for testes development. Similarly, the lack of Sry and the sustained expression of FoxL2 and other genes as well as other currently less known mechanisms drive the also active ovaries' differentiation. Gonadal differentiation into ovaries or testicles leads to different hormonal milieus in females and males, resulting in hormonal organizing and activating (more common) actions at several tissues, including the brain. Within those tissues, chromosomal complement and gonadal steroids act as synergistic or antagonistic proximal factors leading to 
gene expression changes and other cellular modifications that finally to produce or reduce phenotypic differences between females and males. Some of these differences are due to the presence of two $X$ chromosomes in females and subsequent $\mathrm{X}$-inactivation (or escape from inactivation), other differences are due the presence of genes on the $Y$ chromosome not present on the $X$ chromosome and still other differences are due to other chromosomic complement inequalities (figure 3) .

It should be noted that, current views of sexual differentiation have left behind the idea of a "default" or "passive" development of females. On the other hand, as compared to its "traditional" conceptualization, organizational and activational actions of steroids are not longer so rigidly separated and they are currently conceived in a wider sense (see main text). A third major difference between both models (but not properly illustrated in these schemes) is that newer views do not categorize all (not even most) sexually-biased outcomes as binary but rather as being expressed as a continuous.

(These figures are adapted from Arnold AP (2012) The end of gonad-centric sex determination in mammals. Trends Genet 28: 55-61).

\section{Figure 3- Sex complement introduces several sources of genomic bias}

From the zygote stage females and males differ in their sex chromosome complement that might manifest on sex-differences from very early stages of development and throughout the complete individuals' life-span. In the male (A) sex chromosome complement is composed of an $X$ and $Y$ chromosome. In the female (B) there is two $X$ chromosomes, one of which is randomly inactivated 
early in development leading to two distinct cell populations already at the gastrulation stage.

Although $X$ and $Y$ chromosome have in common a series of homologous genes located in the so-called pseudo-autosomal regions (1), $\mathrm{X}$ and $\mathrm{Y}$ chromosome differ on most of their content and activity. Thus, some genes present on the $X$ and $Y$ chromosome (and therefore, usually considered "homologues") actually produce different protein isoforms in males and females (3-3*); that is, they are just pseudo-homologous. Further, there are Y-exclusive genes (4), which are solely expressed in males. Similarly there are X-exclusive genes (2), which at some moments of development might show higher expression on females. Although early in development one the $X$ chromosomes of $X X$ individuals usually gets randomly inactivated though epigenetic mechanisms (5) and the expression of most X-exclusive genes is re-equalized in males and females, some portions of the $X$ chromosome escape this process and some genes (2'), including some pseudo-homologous $X-Y$ genes (3'), keep been expressed at higher levels in females. The inactivation of an $X$ chromosome on $X X$ individuals produces other less explored consequences: First, the inactivated $X$ chromosome remains in the nucleus as a large bulk of heterochromatin (5), which might act as a "sink" for silencing epigenetic factors (6) required at other loci, then leading to the enhanced expression of autosomal genes (not depicted) in $X X$, but not $X Y$, cells. Second, $X$-inactivation affects imprinted genes, which are already subjected to distinct regulations in males and females. Thus, all paternally-imprinted $X$ genes can potentially be expressed (7) in XY 
cells and in XX cells at which parental X chromosome was randomly inactivated whereas only those escaping this process ( $\left.7^{\prime}\right)$ can be expressed in $X X$ cells at which maternal $\mathrm{X}$ chromosome was inactivated. Conversely, all maternally imprinted $\mathrm{X}$-genes can potentially be expressed in $\mathrm{XX}$ cells at which paternal $\mathrm{X}$ chromosome was inactivated (8), but only those escaping this process can be expressed in XX cells at which maternal chromosome was inactivated (8') and none of them are expressed in XY cells.

(in the figure, parental/ maternal origin of chromosomes are denoted by the subscripts $\mathrm{p}$ and $\mathrm{m}$, respectively. Similarly, small arrows denote that just a subset of genes escaping X-inactivation process might be potentially expressed)

Figure 4.- Schematic representation of sex- and gender-biased influences on drug consumption and clinically-related phenomena.

As described in the text, gendered individuals differ in their probability of encountering drugs in the environment, a phenomenon that can mask the propensity of males and females towards drug consumption. On the other hand, once the individuals have taken a drug their sexed bodies might introduce sexrelated biases on the absorbance, distribution and metabolism/ elimination these substances. These potentially distinct amounts of bioavailable drug would then interact with some also sex-biased neurotransmission (i.e., dopaminergic, GABAergic...) systems. This might result in sex-biased reinforcement (as well as in a different propensity/ intensity of unwanted or aversive effects) that will 
affect the individuals' probability of seeking and taking drugs in future occasions. If so, males and females can differ in their proneness to develop drug-related clinical conditions (such as dependence and addiction) and, in such a case, socially gendered factors (along with the activity of the sex-biased organismic activity) might differentially influence the access, engagement and efficacy of any therapeutic attempt intervention.

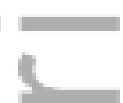

\section{Figure 5.- Proposed scheme for classifying sex/ gender-related}

differences. After the identification of a sex difference, it should be primarily asked whether it is constitutive (that is, ordinarily present) or contingent (that is, arising from an interaction between sex/ gender with any environmental or physiological event; i.e. stress, novelty, etc.).

Regardless its origin, the difference might be expressed as dichotomic (meaning that the outcome presents a clearly bimodal or "two-peaked" distribution) or as a difference of degree; either affecting the groups' averages on a trait, either affecting the frequency at which the trait is present or absent on males and females (number difference).

Finally, differences need to be classified according to their functional significance, as it might result on a divergence between males and males, but also might promote a convergence between them (e.g. when a difference compensate for other existent differences). Thus, for example, $\mathrm{X}$ chromosome inactivation in females should be described as a constitutive dimorphic convergence whereas females' enhanced thigmotaxis in a bright open-field 
should be referred as a contingent average divergence (see main text for further details).

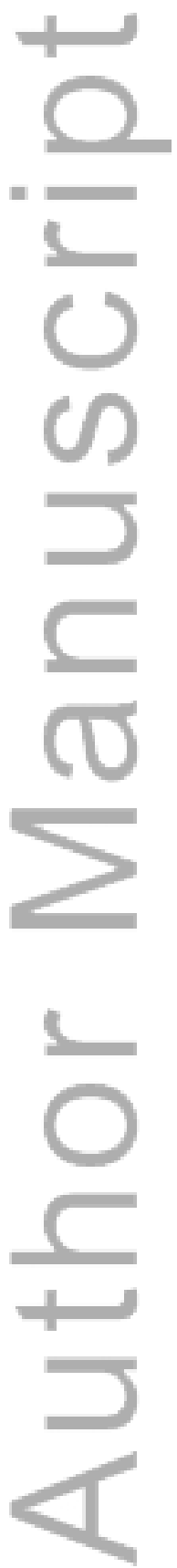

This article is protected by copyright. All rights reserved. 


\section{REFERENCES}

Arnold AP and Burgoyne PS (2004) Are XX and XY cells intrinsically different? Trends Endocrin Met 15:6-11.

Arnold AP (2009) The organizational-activational hypothesis as the foundation for a unified theory of sexual differentiation of all mammalian tissues. Horm Behav 55: 570-578.

Arnold AP (2012) The end of gonad-centric sex determination in mammals. Trends Genet 28 : $55-61$.

Barker JM, Torregrossa MM, Arnold AP, Taylor JR (2010) Dissociation of genetic and hormonal influences on sex differences in alcoholism-related behaviors. J Neurosci 30: 9140-9144.

Becker JB and Hu M (2008) Sex differences in drug abuse. Front Neuroendocrinol 29: 36-47.

Becker JB (2009). Sexual differentiation of motivation: a novel mechanism?. Hormon Behav 55: 646-654.

Becker JB, Perry AN and Westenbroek C. (2012). Sex differences in the neural mechanisms mediating addiction: a new synthesis and hypothesis. Biol Sex Differ 3: 1-35.

Beiko J, Lander R, Hampson E, Boon F, Cain DP (2004) Contribution of sex differences in the acute stress response to sex differences in water maze performance. Behav Brain Res 151:239-253.

Bellott DW, Hughes JF, Skaletsky H, Brown LG, Pyntikova T, Cho TJ, ... and Page, D. C. (2014) Mammalian $\mathrm{Y}$ chromosomes retain widely expressed dosage-sensitive regulators. Nature 508: 494-499.

Berletch JB, Yang F, Xu J, Carrel L, Disteche CM (2011) Genes that escape from X inactivation. Human Genet 130: 237-245.

Bisagno V and Cadet JL (2014) Stress, sex, and addiction: potential roles of corticotropinreleasing factor, oxytocin, and arginine-vasopressin. Behav Pharmacol 25: 445-457.

Bourc'his D and Proudhon C (2008) Sexual dimorphism in parental imprint ontogeny and contribution to embryonic development. Mol Cell Endocinol 282: 87-94.

This article is protected by copyright. All rights reserved. 
Botbol M, Roubertoux PL, Carlier, M, Trabado S, Brailly-Tabard S, Pérez-Díaz F, Bonnot O, Bronsard G, Torjdman S (2011) Modulation of brain eendorphin concentration by the specific part of the y chromosome in mice. PLOS ONE 6: 1-5

Brady KT, Randall CL. (1999) Gender differences in substance use disorders. Psychiatr Clin North Am 22: 241-52.

Brennan J and Capel B (2004) One tissue, two fates: molecular genetic events that underlie testis versus ovary development. Nat Rev Genet 5: 509-521.

Carrel L and Willard HF (2005) X-inactivation profile reveals extensive variability in X-linked gene expression in females. Nature 434: 400-404.

Carroll ME and Anker JJ (2011) Sex differences and ovarian hormones in animal models of drug dependence. Horm Behav 58: 44-56.

Caruso D, Pesaresi M, Abbiati F, Calabrese D, Gatti S, Garcia-Segura LM, Melcang RC (2013) Comparison of plasma and cerebrospinal fluid levels of neuroactive steroids with their brain, spinal cord and peripheral nerve levels in male and female rats. Psychoneuroendocrinology 38: $2278-2290$

Chambers RA, Taylor JR and Potenza MN (2003) Developmental neurocircuitry of motivation in adolescence: a critical period of addiction vulnerability. Am J Psychiatry 160: 1041-1052.

Champagne FA and Curley JP (2009). Epigenetic mechanisms mediating the long-term effects of maternal care on development. Neurosci Biobehav Rev 33: 593-600.

Clayton JA and Collins FS. (2014). NIH to balance sex in cell and animal studies. Nature, 509, 15.

Coe, R. (2002). It's the Effect Size, Stupid. Paper presented at the British Educational Research Association annual conference (Vol. $\quad 12, \quad$ p. $\quad 14)$. http://www.assessment4excellence.org/attachments/ebe/ESguide.pdf Cox $\mathrm{KH}$, Bonthuis PJ and Rissman EF (2014). Mouse model systems to study sex chromosome genes and behavior: relevance to humans. Front Neuroendocrinol 35:405-419.

This article is protected by copyright. All rights reserved. 
Czech DP, Lee J, Sim H, Parish CL, Vilain E, Harley VR (2012) The human testis-determining factor SRY localizes in midbrain dopamine neurons and regulates multiple components of catecholamine synthesis and metabolism. J Neurochem 122: 260-271

Davies, W and Wilkinson LS (2006) It is not all hormones: alternative explanations for sexual differentiation of the brain. Brain Res 1126: 36-45.

DeVries GJ (2004) Sex Differences in Adult and Developing Brains: Compensation, Compensation, Compensation. Endocrinology 145:1063-1068

Dewing P, Chiang CW, Sinchak K, Sim H, Fernagut PO, Kelly S, Chesselet MF, Micevych PE, Albrecht KH, Harley VR, Villain E (2006) Direct regulation of adult brain function by the malespecific factor SRY. Current Biol 16: 15-20.

Du S, Itoh N, Askarinam S, Hill H, Arnold AP, Voskhul RR (2013) XY sex chromosome complement, compared with $\mathrm{XX}$, in the CNS confers greater neurodegeneration during experimental autoimmune encephalomyelitis Proc. Natl Acad. Sci USA 111: 2806-2011

Ellengren $\mathrm{H}$ and Parch $\mathrm{J}$ (2007) The evolution of sex-biased genes and sex-biased gene expression. Nature Rev Genet 8: 689-698

Fattore L, Melis M, Fadda P and Fratta, W (2014) Sex differences in addictive disorders. Front Neuroendocrinol 35: 272-284.

Fox HC, Morgan PT and Sinha R (2014). Sex differences in guanfacine effects on drug craving and stress arousal in cocaine-dependent individuals. Neuropsychopharmacology, 39: 15271537

Georges A, Auguste A, Bessière L, Vanet A, Todeschini AL, Veitia RA (2014) FOXL2: a central transcription factor of the ovary. J Mol Endocrinol 52: R17-R33.

Gregg C, Zhang J, Butler JE, Haig D, Dulac C (2010a) Sex-Specific Parent-of-Origin Allelic Expression in the Mouse Brain. Science $329: 682-685$.

Gregg C, Zhang J, Weissbourd B, Luo S, Schroth GP, Haig D, Dulac C (2010b) High-Resolution Analysis of Parent-of-Origin Allelic Expression in the Mouse Brain. Science 329: 643-648

This article is protected by copyright. All rights reserved. 
HaoY, Huang W, Nielsen DA and Kosten TA (2011) Litter gender composition and sex affect maternal behavior and DNA methylation levels of the oprm1 gene in rat offspring. Front Psychiatry 2.

Hernandez-Avila CA, Rounsaville BJ and Kranzler HR (2004) Opioid-, cannabis-and alcoholdependent women show more rapid progression to substance abuse treatment. Drug Alcohol Depend 74: 265-272.

John $U$ (1987) Alcohol-dependent men and women in detoxification: some comparisons. Alcohol Clin Exp Res 11: 155-157

Juraska JM, Sisk CL and DonCarlos LL (2013). Sexual differentiation of the adolescent rodent brain: hormonal influences and developmental mechanisms. Horm Behav 64: 203-210.

Knudsen E (2004) Sensitive periods in the development of the brain and behavior. J Cogn Neurosci 16: 1412-1425.

Kobayashi S, Isotani A, Mise N, Yamamoto M, Fujihara Y, Kaseda K., ... and Okabe M (2006). Comparison of Gene Expression in Male and Female Mouse Blastocysts Revealed Imprinting of the X-Linked Gene Rhox5/Pem at Preimplantation Stages. Current Biol 16: 166-172.

Konkle ATM and McCarthy MM (2011) Developmental time course of estradiol, testosterone, and dihydrotestosterone levels in discrete regions of male and female rat brain. Endocrinology 152: $223-235$

Lenz K. M, Nugent BM and McCarthy MM (2012) Sexual differentiation of the rodent brain: dogma and beyond. Front Neurosci 6.

Lewis B, Hoffman LA and Nixon SJ (2014) Sex differences in drug use among polysubstance users. Drug Alcohol Depend 145: 127-133.

Lister R, Mukamel EA, Nery JR, Urich M, Puddifoot CA, Johnson ND ... and Ecker JR. (2013) Global epigenomic reconfiguration during mammalian brain development. Science 341: 1237905-1237905.

Lynch WJ, Roth ME, Mickelberg JL, Carroll ME (2001) Role of estrogen in the acquisition of intravenously self-administered cocaine in female rats. Pham Biochem Behav 68: 461-466.

This article is protected by copyright. All rights reserved. 
McCarthy M and Konkle A (2005). When is a sex difference not a sex difference?. Front Neuroendocrinol 26: 85-102.

McCarthy MM (2010) How it's made: organisational effects of hormones on the developing brain. J Neuroendocrinol 22: 736-742.

McCormick CM, Mathews IZ. Thomas C, Waters P (2010). Investigations of HPA function and the enduring consequences of stressors in adolescence in animal models. Brain Cogn 72: 7385.

McCarthy MM, Arnold AP,. Ball GF,. Blaustein JD, and.De Vries GJ (2012) Sex Differences in the Brain: The Not So Inconvenient Truth. J Neurosci. 15: 2241-2247

Mertens JR and Weisner CM (2000) Predictors of substance abuse treatment retention among women and men in an HMO. Alcohol Clin Exp Res 24: 1525-1533.

Moore CL and Morelli GA (1979). Mother rats interact differently with male amd female offspring. J Comp Physiol Psych 93: 677.

Morgan CP and Bale TL (2012) Sex differences in microRNA regulation of gene expression: no smoke, just miRs. Biol Sex Differ, 3: 22.

Nakagawa S and Cuthill IC (2007) Effect size, confidence interval and statistical significance: a practical guide for biologists. Biol Rev ;82:591-605.

Noori HR, Helinski S and Spanagel R (2014). Cluster and meta- analyses on factors influencing stress-induced alcohol drinking and relapse in rodents. Addiction biology, 19(2), 225-232.

Nguyen DK, Disteche CM (2006) High expression of the mammalian $X$ chromosome in brain. Brain Res 1126:46-49

Ober C, Loisel DA and Gilad Y (2008) Sex-specific genetic architecture of human disease. Nat Rev Genet 9: 911-922.

Paus T., Nawaz-Khan I, Leonard G, Perron M, Pike GB, Pitiot A, ... and Pausova Z (2010) Sexual dimorphism in the adolescent brain: role of testosterone and androgen receptor in global and local volumes of grey and white matter. Horm Behav 57: 63-75.

This article is protected by copyright. All rights reserved. 
Perry, A. N., Westenbroek, C., Becker J. B. Impact of pubertal and adult estradiol treatments on cocaine self-administration (2013) Horm Behav 64: 573-578.Perry, A. N., Westenbroek, C., and Becker, J. B., The Development of a Preference for Cocaine Over Food Identifies Individual Rats with Addiction-like Behaviors (2013b) PLoS One 8:e79465.

Phoënix CH, Goy RW, Gerall AA, WC (1959). Organizing action of prenatally administered testosterone propionate on the tissues mediating mating behavior in the female guinea pig. Endocrinology 65, 369-382.

Plath K, Mlynarczyk-Evans S, Nusinow DA, Panning B (2002). Xist RNA and the Mechanism of X Chromosome Inactivation. Ann Rev Genet 36: 233-278.

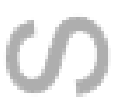

Quinn JJ, Hitchcott PK, Umeda,EA, Arnold AP, Taylor JR (2007) Sex chromosome complement regulates habit formation. Nature Neurosci,10: 1398-1400.

Quinones-Jenab V and Jenab S (2012) Influence of sex differences and gonadal hormones on cocaine addiction. ILAR 53: 14-22

Reinius B, Shi C, Hengshuo L, Sandhu KS, Radomska KJ, Rose GD... and Jazin E (2010) Female-biased expression of long non-coding RNAs in domains that escape X-inactivation in mouse. BMC genomics 11:614.

Schulz, KM, Molenda-Figueira, HA \& Sisk CL (2009) Back to the future: the organizationalactivational hypothesis adapted to puberty and adolescence. Horm Behav 55: 597-604.

Seney ML, Ekong KI, Ding Y, Tseng GC, Sibille E (2013) Sex chromosome complement regulates expression of mood-related genes. Biol Sex Diff 4: 20.

Seu E, Groman SM, Arnold AP, Jentsch JD (2014) Sex Chromosome Complement Influences Operant Responding for a Palatable Food in Mice. Genes, Brain and Behav 13: 527-534.

This article is protected by copyright. All rights reserved. 
Srivastava DP, Waters EM, Mermelstein PG, Kramár EA, Shors TJ, Liu F (2011) Rapid estrogen signaling in the brain: implications for fine tunning of neuronal circuitry. $J$ Neurosci 31:16056-16063.

Spear LP (2000) The adolescent brain and age-related behavioral manifestations Neurosci

Biobehav Rev 24: 417-463.

Steinberg L (2008) A social neuroscience perspective on adolescent risk-taking. Dev Re 28: 78106.

Van Etten ML, Neumark YD and Anthony JC (1999). Male-female differences in the earliest stages of drug involvement. Addiction, 9: 1413-1419.

Van Etten ML, Anthony JC (2001) Male-female differences in transitions from first drug opportunity to first use: searching for subgroup variation by age, race, region, and urban status. J Womens Health Gend Based Med 10:797-804.

Van Nas A GuhaThakurta A, Wang SS, Yehya N, Horvath, S, Zhang, B., ... and Lusis, AJ (2009) Elucidating the role of gonadal hormones in sexually dimorphic gene coexpression networks. Endocrinology, 150: 1235-1249.

Waxman DJ and O'Connor C (2006) Growth hormone regulation of sex-dependent liver gene expression. Molecular Endocrinol 20: 2613-2629

Weisner C and Schmidt L (1992) Gender disparities in treatment for alcohol problems. JAMA 268: 1872-1876.

Wijchers PJ, Yandim C, Panousopoulou E, Ahmad M, Harker N, Saveliev N, ... and Festenstein R (2010). Sexual Dimorphism in Mammalian Autosomal Gene Regulation Is Determined Not Only by sry but by Sex Chromosome Complement As Well. Developmental Cell, 19: 477-484.

$\mathrm{Xu} \mathrm{J}$, Deng $\mathrm{X}$ and Disteche CM (2008) Sex-specific expression of the X-linked histone demethylase gene Jarid1c in brain. PLOS ONE : e2553.

This article is protected by copyright. All rights reserved. 
Yang X, Schadt EE, Wang S, Wang H, Arnold AP, Ingram-Drake L, ... and Lusis, AJ (2006). Tissue-specific expression and regulation of sexually dimorphic genes in mice. Genome Res 16. 995-1004.

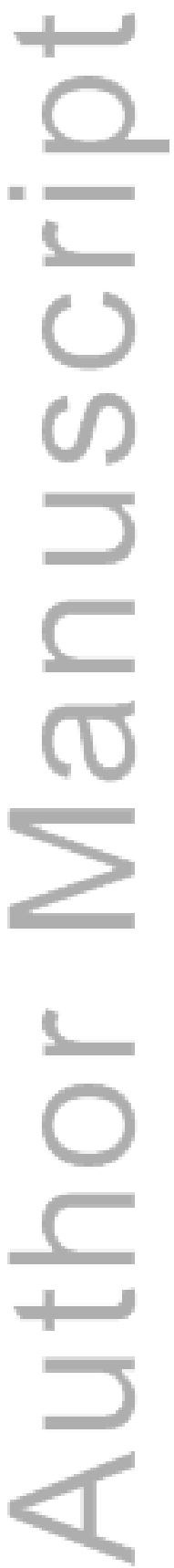

This article is protected by copyright. All rights reserved. 


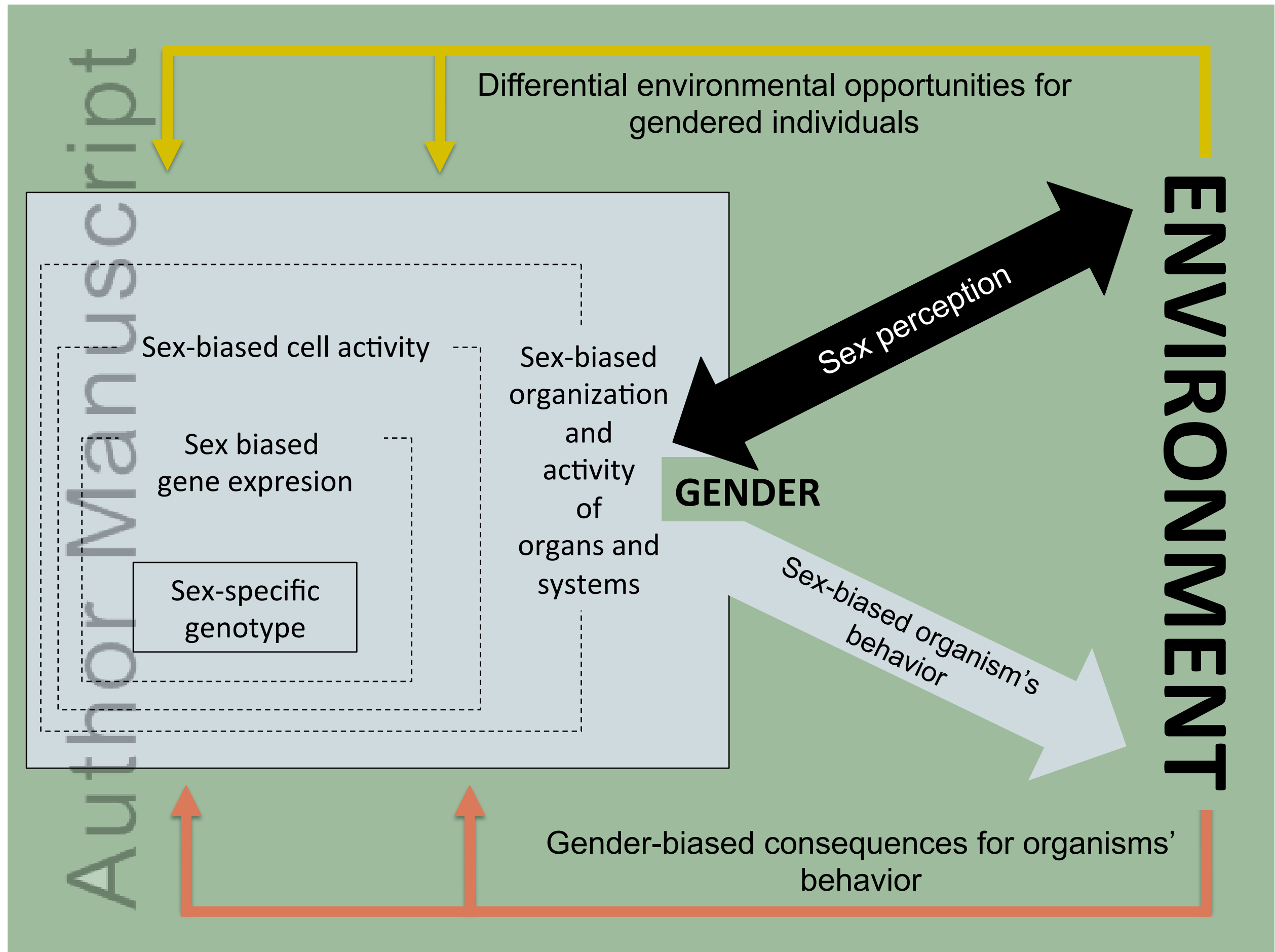




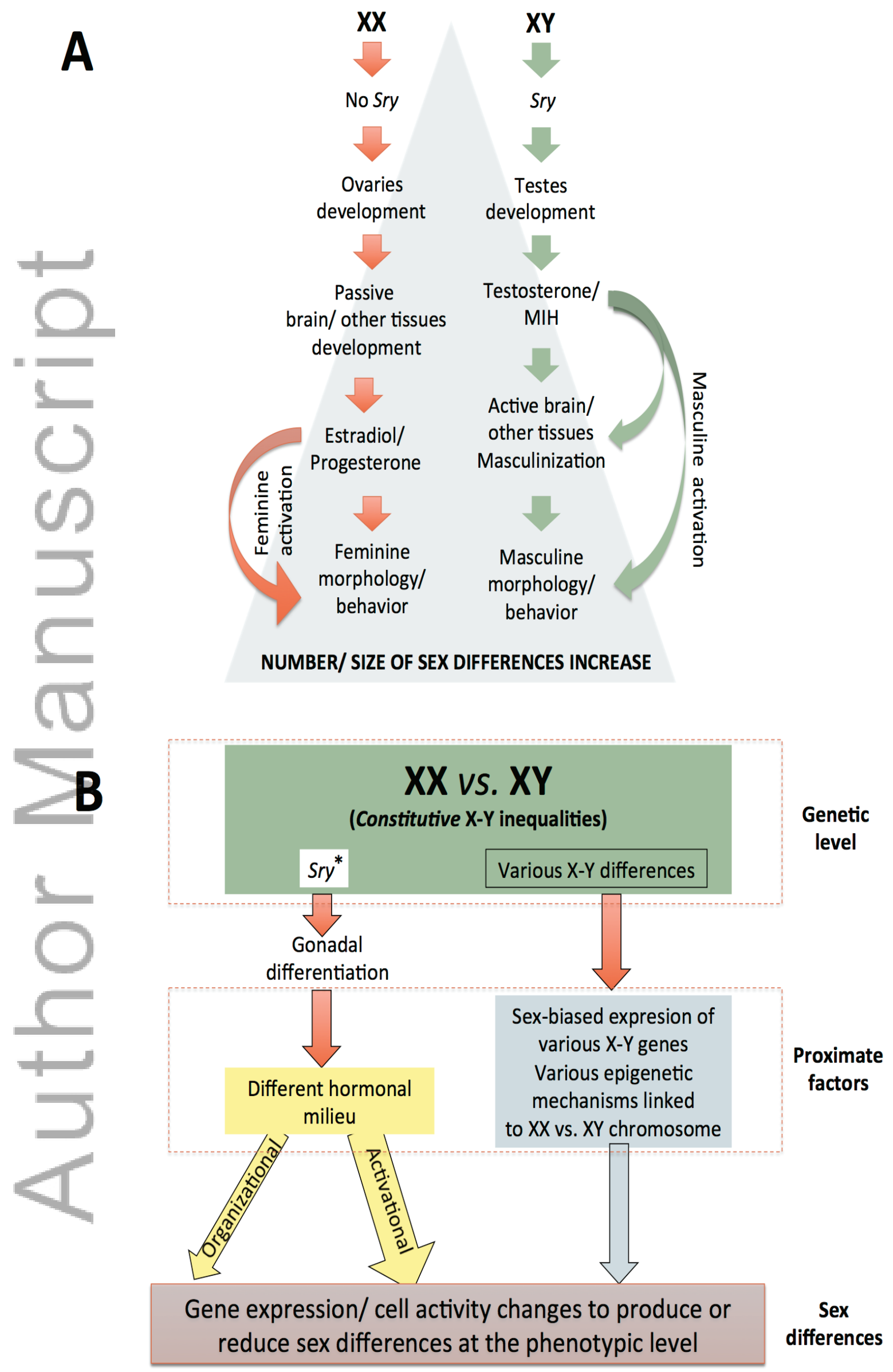

This article is protected by copyright. All rights reserved. 


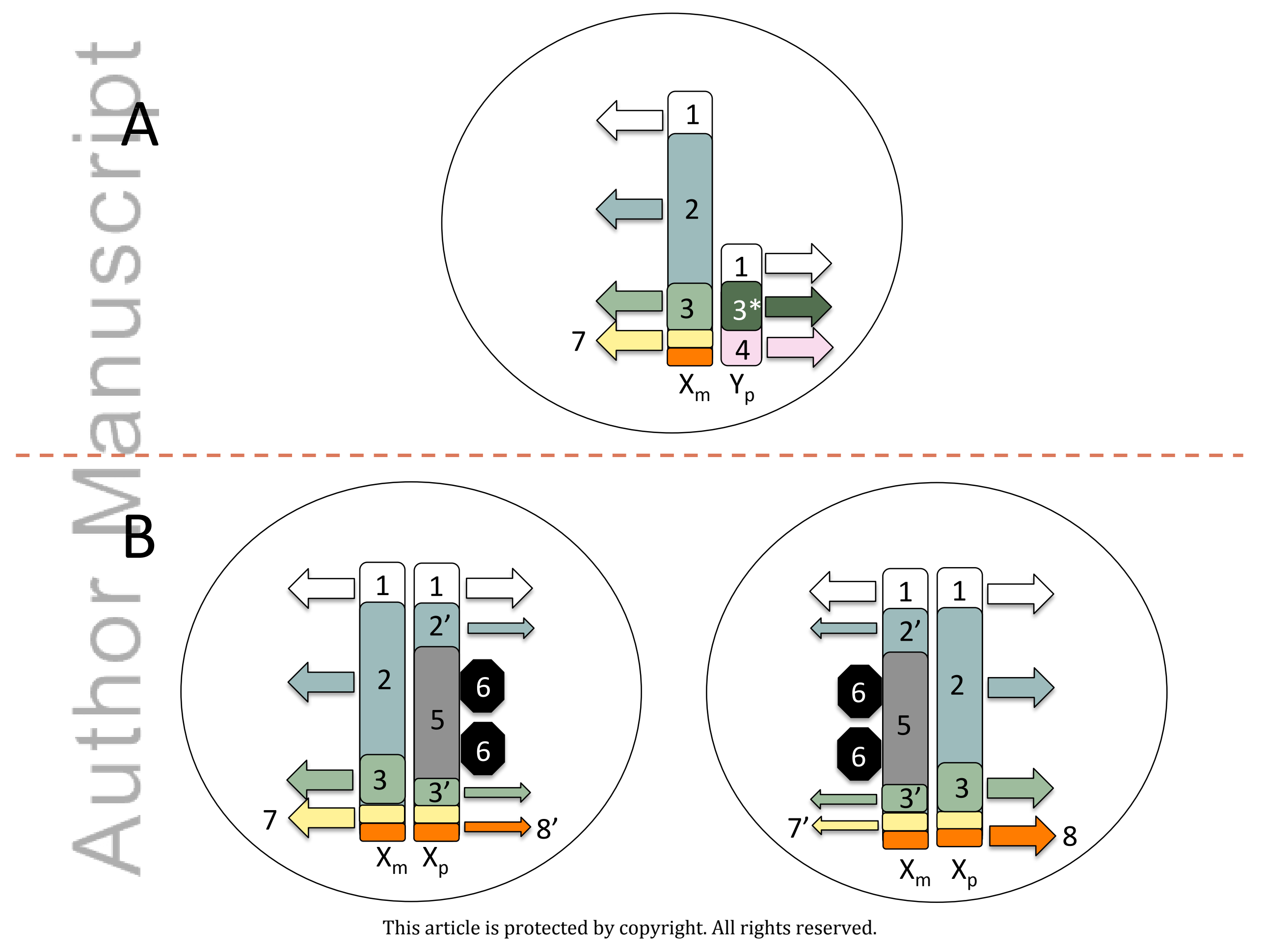




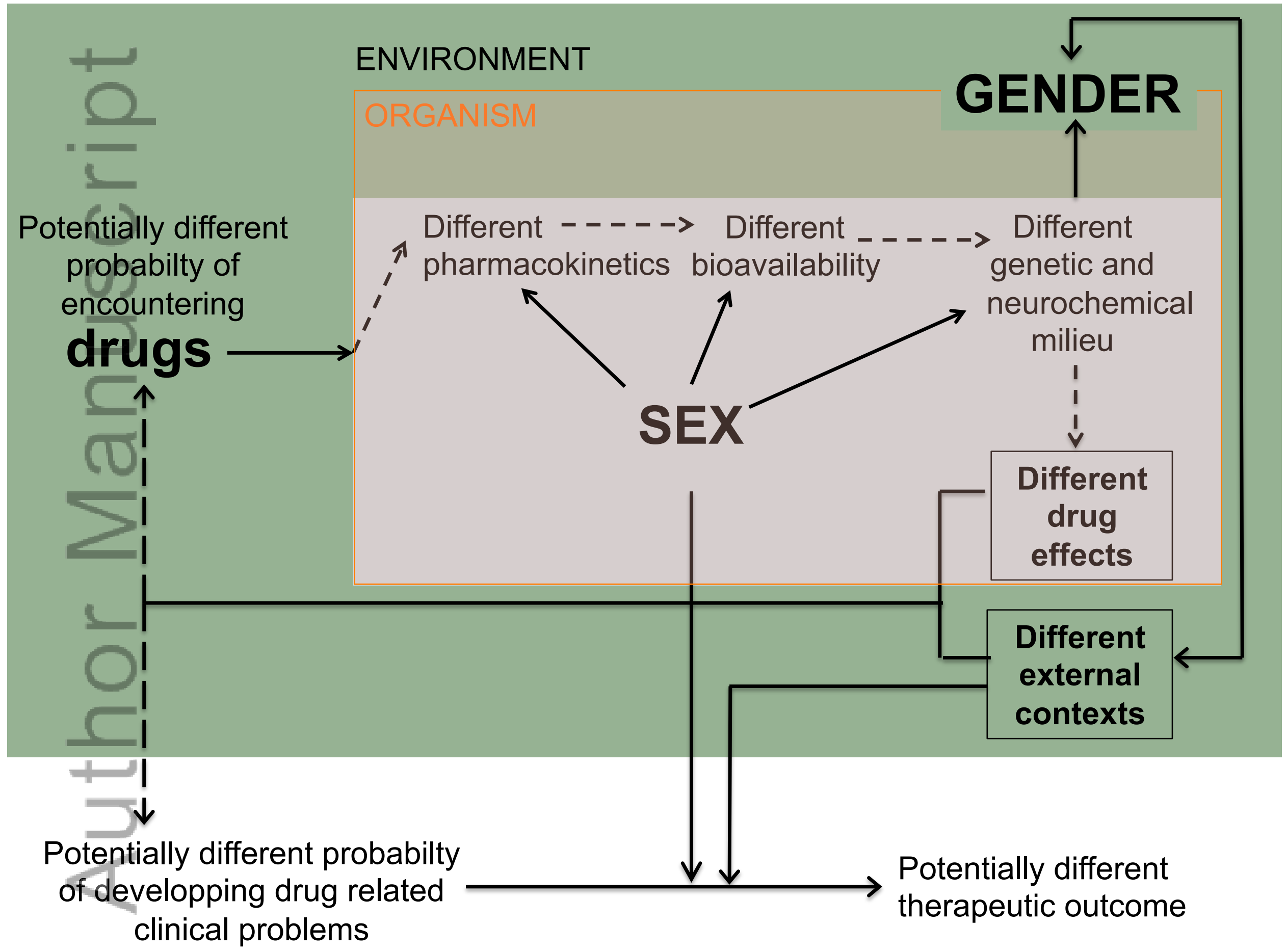




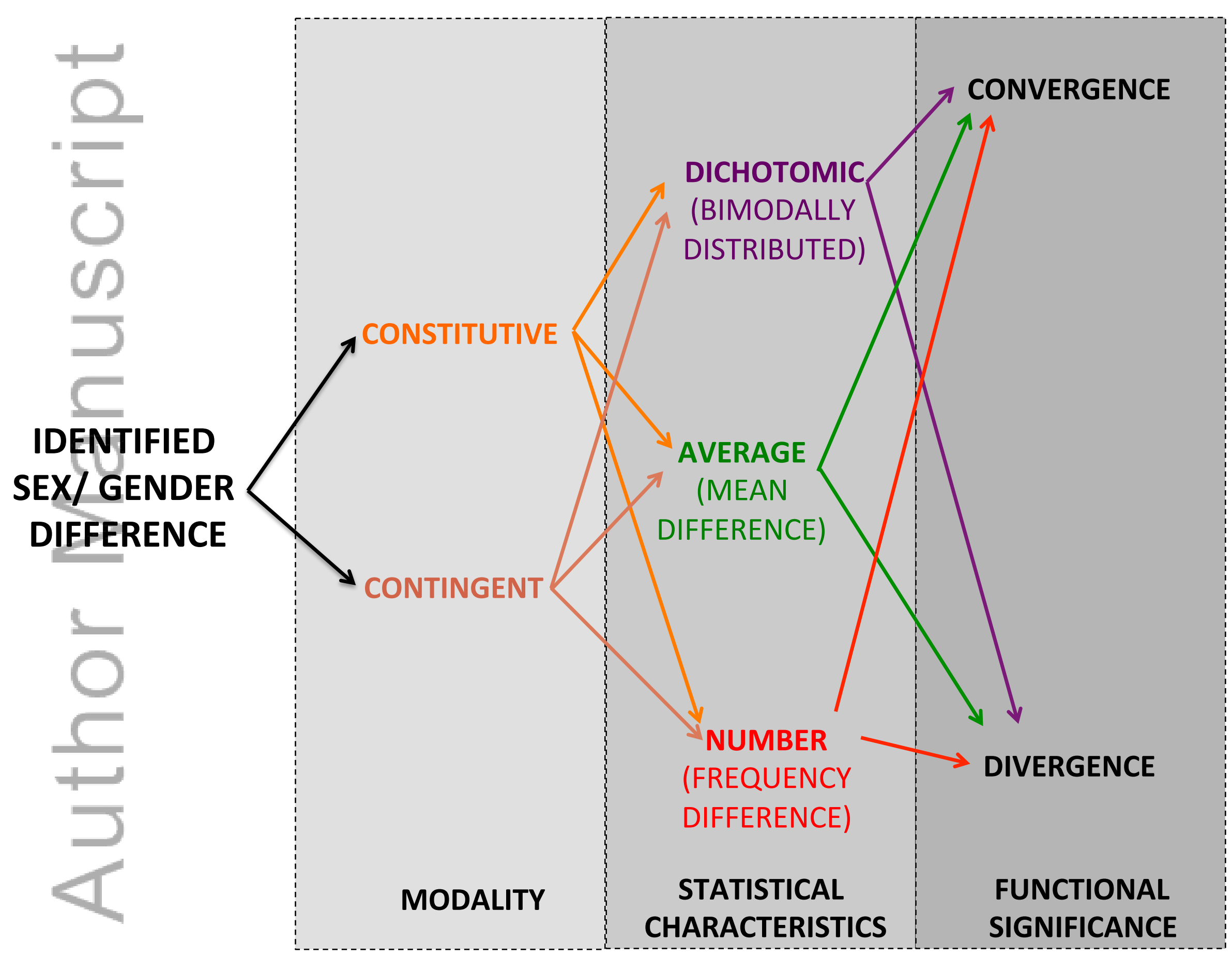

This article is protected by copyright. All rights reserved. 